Borneo Journal of Phamascientech, Vol. 04, No. 01, April Tahun 2020

ISSN-Print. 2541-3651

ISSN-Online. 2548 - 3897

Research Article

\title{
HUBUNGAN PENGELOLAAN OBAT INSTALASI FARMASI TERHADAP KUALITAS PELAYANAN KESEHATAN DAN DAMPAKNYA TERHADAP KINERJA RSUD XYZ
}

\section{THE RELATIONSHIP BETWEEN PENGELOLAAN OBAT AND THE QUALITY OF HEALTH SERVICES AND ITS IMPACT ON THE PERFORMANCE OF XYZ DISTRIC HOSPITAL}

\author{
Liska Marlindasari $^{1, *}$, MGS Aritonang ${ }^{2}$, Tedy Herdiana ${ }^{3}$ \\ ${ }^{1}$ STIKes Muhammadiyah Kuningan, ${ }^{2,3}$ Universitas Pancasila Jakarta \\ *marlindaliska@gmail.com
}

\begin{abstract}
ABSTRAK
Penerapan program Jaminan Kesehatan Nasional (JKN) telah membuat permintaan obat semakin meningkat. Namun, kurangnya persediaan diketahui telah menyebabkan terjadinya kekosongan obat yang berpengaruh terhadap kinerja rumah sakit. Varibel dalam penelitian ini terdiri dari variable bebas yaitu Pengelolaan Obat, variable penghubung yaitu kualitas pelayanan kesehatan dan varibel terikat yaitu kinerja RSUD XYZ. Pada penelitian deskriptif analitik ini dilakukan pendekatan cross sectional dan diambil 100 pasien sebagai sampel secara random. Data primer diperoleh melalui wawancara kuesioner terstruktur dan dianalisis dengan menggunakan uji regresi logistik berganda. Secara umum, hasil penelitian menunjukkan: 36,8\% responden berpendapat bahwa kualitas Pengelolaan Obat tidak baik, 36,0 \% ragu terhadap kualitas pelayanan kesehatan, dan $41,0 \%$ setuju bahwa kinerja RSUD XYZ baik. Hasil uji Pearson's correlation menunjukkan ada hubungan antara Pengelolaan Obat dan kualitas pelayanan $(\mathrm{p}<0,05$, CI $95 \%)$ dengan pengadaan sebagai indikator paling dominan $(\mathrm{B}=1,343)$. Selain itu, ada hubungan antara kualitas pelayanan dan kinerja ( $<<0,05, \mathrm{CI} 95 \%$ ), dengan bukti fisik sebagai indikator paling dominan $(B=1,299)$ serta antara Pengelolaan Obat dan kinerja ( $p<0,05, C I$ 95\%), dengan internal bisnis $(B=1,239)$ dan pelanggan $(B=1,012)$ sebagai faktor paling dominan.
\end{abstract}

Kata Kunci: Pengelolaan Obat, kualitas pelayanan kesehatan, kinerja 
Borneo Journal of Phamascientech, Vol. 04, No. 01, April Tahun 2020

ISSN-Print. 2541-3651

ISSN-Online. 2548 - 3897

Research Article

\begin{abstract}
The implementation of Jaminan Kesehatan Nasional (JKN, National Health Insurance) program has increased drug demand. However, a lack of inventory is known to have caused drug stock-out that affected hospital performance. In this descriptive analytic study a cross sectional approach was used and 100 patients were taken as a random sample. Primary data were obtained through structured questionnaire interviews and analyzed using multiple logistic regression tests. In general, the results of the study showed: $36.8 \%$ of respondents thought that the quality of Pengelolaan Obat was not good, $36.0 \%$ were doubtful about the quality of health services, and $41.0 \%$ agreed that the performance of $X Y Z$ District Hospital was good. Pearson's correlation test results showed there was a relationship between Pengelolaan Obat and service quality ( $p<0.05,95 \% C I)$ with procurement as the most dominant indicator $(B=1.343)$. In addition, there is a relationship between service quality and performance ( $p<0.05,95 \% C I)$, with physical evidence as the most dominant indicator $(B=1.299)$ and between Pengelolaan Obat and performance ( $p<0.05$, 95\% CI ), with internal business $(B=1,239)$ and customers $(B=1,012)$ as the most dominant factor.
\end{abstract}

Keywords: Pengelolaan Obat, quality of health services, performance

\section{PENDAHULUAN}

RSUD XYZ adalah rumah sakit milik pemerintah Kabupaten Kuningan kelas B, Dengan status RSUD XYZ sebagai salah satu RS milik pemerintah daerah maka dituntut untuk terus menerus meningkatkan kinerja agar dapat melayani pasien secara penuh.

Ada 5 revenue center dalam rumah sakit, salah satunya instalasi farmasi. Instalasi farmasi merupakan salah satu revenue center utama mengingat lebih dari $90 \%$ pelayanan kesehatan di rumah sakit menggunakan perbekalan farmasi dan $50 \%$ dari seluruh pemasukan rumah sakit berasal dari pengelolaan perbekalan farmasi. Sudah dapat diprediksi bahwa pendapatan rumah sakit akan mengalami penurunan jika masalah perbekalan farmasi tidak dikelola secara cermat serta penuh tanggung jawab.

Dari data yang didapat di RSUD XYZ diperoleh informasi bahwa seringnya terjadi kekosongan obat karena peneglolaan yang tidak baik di RSUD XYZ. Hal ini Menyebabkan penurunan pendapatan 
Borneo Journal of Phamascientech, Vol. 04, No. 01, April Tahun 2020

ISSN-Print. 2541-3651

ISSN-Online. 2548 - 3897

Research Article

pada RSUD XYZ dan keluhan terhadap pelayanan kesehatan. Untuk mengatasi kekurangan ini, maka perlu dilakukan analisis pengaruh pengelolaan obat terhadap kualitas pelayanan kesehatan serta dampaknya terhadap kinerja, karena mengingat pengelolaan yang baik sangat penting untuk meningkatkan efisiensi kulitas pelayanan kesehatan.

\section{METODOLOGI}

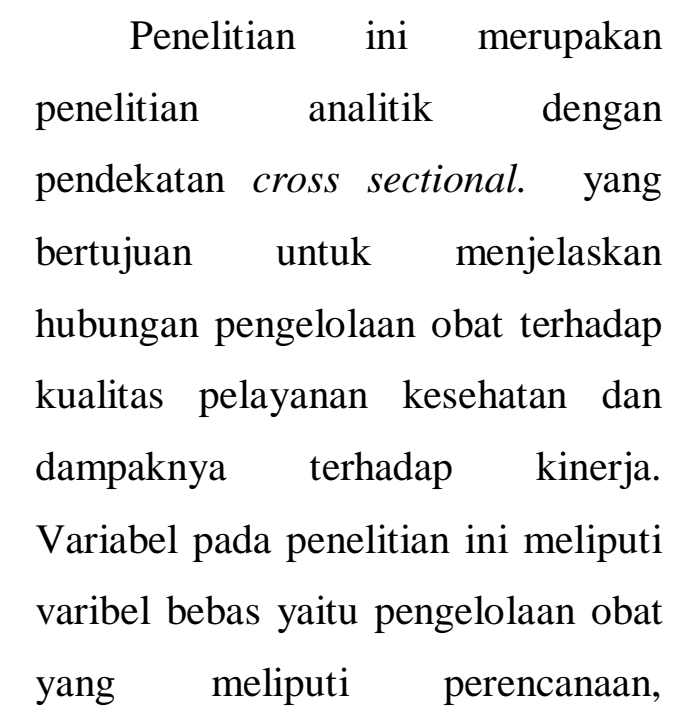
pengadaan, pengawasan dan pengendalian. Varibel intervening yaitu kualitas pelayanan kesehatan yang meliputi bukti fisik, keandalan, daya tanggap, jaminan dan empati. Variabel terikat yaitu kinerja yang meliputi pelanggan, keuangan, interal bisnis dan pembejaran dan

pertumbuhan. Sedangkan data yang digunakan dalam penelitian ini adalah data primer dan data sekunder. Data primer merupakan interview dengan pasien dan data sekunder merupakan informasi yang bersumber dari literatur. Populasi dalam penelitian ini adalah seluruh pasien dan karyawan RSUD XYZ selama waktu pengumpulan data bulan Juni 2019. Sampel dalam penelitian ini adalah jumlah dari keseluruhan populasi (total sampling) yang telah dihitung menggunakan rumus slovin maka didapat sampel sebanyak 100 orang. Tenkik pengambilan sampel yaitu secara accidental sampling, karena meningat jumlah sampel yang digunakan tidak hanya pada pasien melainkan karyawan. Adapun syarat yang ditentukan adalah responden bisa berkomunikasi dan bersedia untuk diwawancarai. Data yang diperoleh melalui kuesioner diolah menggunakan analisa statistik dengan bantuan software SPSS versi 23. Pengujian yang dilakukan terhadap data antara lain uji validitas, uji realibilitas, dan analisa deskriptif 
Borneo Journal of Phamascientech, Vol. 04, No. 01, April Tahun 2020

ISSN-Print. 2541-3651

ISSN-Online. 2548 - 3897

Research Article

(uji bivariat, multivariat dan univariat).

\section{HASIL DAN PEMBAHASAN}

\section{Hubungan Pengelolaan Obat terhadap Kualitas Pelayanan}

Tabel I. Uji Korelasi 1

\begin{tabular}{|l|l|r|r|}
\hline $\begin{array}{ll}\text { Kualitas } \\
\text { Pelayanan }\end{array}$ & Pearson & 1 &, $930^{-}$ \\
& Correlation & & \\
& Sig.(2-tailed) & &, 000 \\
& $\mathrm{~N}$ & 100 & 100 \\
\hline Kinerja & Pearson &, $930^{-}$ & 1 \\
& Correlation & & \\
& Sig. (2-tailed) &, 000 & \\
& $\mathrm{~N}$ & 100 & 100 \\
\hline
\end{tabular}

Hasil analisis menunjuk kan bahwa terdapat hubungan Pengelolaan Obat terhadap kualitas pelayanan kesehatan. Hasil analisis menunjukan signifikansi hubungan yang sangat kuat antara Pengelolaan Obat dengan kinerja yaitu sebesar 0,000 ( $<$ 0,005). Hasil analisis pearson correlation menunjukan hasil 0,964 yaitu tingkat hubungan antara Pengelolaan Obat dan kualitas pelayanan kesehatan adalah sempurna.

Untuk mengetahui faktor yang paling berhubungan terhadap Kualitas Pelayanan Kesehatan RSUD
XYZ, maka dilakukan analisis multivariat antara variabel bebas dengan variabel terikat. Dengan melihat nilai $\mathrm{B}$, hasil penelitian menunjukan bahwa dari 4 variabel yang diuji secara bersamaan faktor yang paling dominan adalah Pengadaan ( $\mathrm{B}=1,343)$. Hasil analisis hubungan Pengelolaan Obat terhadap kualitas pelayanan kesehatan Instalasi farmasi RSUD XYZ dapat dilihat pada Tabel II.

Tabel II. Variabel Penelitian 1

\begin{tabular}{|r|l|c|c|}
\hline No & $\begin{array}{l}\text { Variabel } \\
\text { Penelitian }\end{array}$ & B & $\boldsymbol{P}$ \\
\hline 1 & Perencanaan & 1,193 & 0,004 \\
\hline 2 & Pengadaan & $\mathbf{1 , 3 4 3 * *}$ & 0,001 \\
\hline 3 & Pengawasan & $-0,251$ & 0,538 \\
\hline 4 & Pengendalian & 0,418 & 0,309 \\
\hline
\end{tabular}

\section{Hubungan Kualitas Pelayanan Kesehata terhadap Kinerja}

Tabel III. Uji Korelasi 2

\begin{tabular}{|c|c|c|c|}
\hline \multirow[t]{3}{*}{$\begin{array}{l}\text { Kualitas } \\
\text { Pelayanan }\end{array}$} & $\begin{array}{l}\text { Pearson } \\
\text { Correlation }\end{array}$ & 1 &, $930^{-}$ \\
\hline & Sig. (2-tailed) & &, 000 \\
\hline & $\mathrm{N}$ & 100 & 100 \\
\hline \multirow[t]{3}{*}{ Kinerja } & $\begin{array}{l}\text { Pearson } \\
\text { Correlation }\end{array}$ &, $930^{-}$ & 1 \\
\hline & Sig. (2-tailed) &, 000 & \\
\hline & $\mathrm{N}$ & 100 & 100 \\
\hline
\end{tabular}


Borneo Journal of Phamascientech, Vol. 04, No. 01, April Tahun 2020

ISSN-Print. 2541-3651

ISSN-Online. 2548 - 3897

Research Article

Hasil analisis menunjukan bahwa terdapat hubungan kualitas Pelayanan Kesehatan terhadap kinerja. Hasil analisis menunjukan signifikansi hubungan yang sangat kuat antara kualitas pelayanan kesehatan dengan kinerja yaitu sebesar $0,000(<0,005)$. Hasil analisis pearson correlation menunjukan hasil 0,930 yaitu tingkat hubungan antara kualitas pelayanan kesehatandan kinerja adalah sempurna.

Untuk mengetahui faktor yang paling berhubungan terhadap kinerja RSUD XYZ, maka dilakukan analisis multivariat antara variabel bebas dengan variabel terikat. Dengan melihat nilai $B$, hasil penelitian menunjukan bahwa dari 5 variabel yang diuji secara bersamaan faktor yang paling dominan adalah Bukti Fisik ( $\mathrm{B}=1,299)$. Hasil analisis hubungan Kualitas Pelayanan Kesehatan terhadap Kinerja
Tabel IV. Variabel Penelitian 2

\begin{tabular}{|l|l|r|r|}
\hline No & $\begin{array}{l}\text { Variabel } \\
\text { Penelitian }\end{array}$ & \multicolumn{1}{l|}{ B } \\
\hline 1 & Bukti Fisik & $\mathbf{1 , 2 9 9}$ & 0,005 \\
\hline 2 & Keandalan & 0,733 & 0,07 \\
\hline 3 & Daya Tanggap & $-0,924$ & 0,041 \\
\hline 4 & Jaminan & $-0,125$ & 0,764 \\
\hline 5 & Empati & $-1,037$ & 0,016 \\
\hline
\end{tabular}

\section{Hubungan Pengelolaan}

Obat terhadap kinerja

Tabel V. Uji Korelasi 3

\begin{tabular}{|l|l|r|r|}
\hline \multirow{4}{*}{ Kinerja } & Pearson & 1 &, $915^{-}$ \\
& Correlation & & \\
\cline { 2 - 2 } & Sig. (2-tailed) & &, 000 \\
\cline { 2 - 2 } & $\mathrm{N}$ & 100 & 100 \\
\hline \multirow{2}{*}{ Pengelolaan } & Pearson &, $915^{-}$ & 1 \\
& Correlation &, 000 & \\
\cline { 2 - 2 } & Sig. (2-tailed) & 100 & 100 \\
\cline { 2 - 3 } & $\mathrm{N}$ & & \\
& & & \\
\end{tabular}

Hasil analisis menunjukan bahwa terdapat hubungan Pengelolaan Obat terhadap kinerja. Hasil analisis menunjukan signifikansi hubungan yang sangat kuat antara Pengelolaan Obat dengan kinerja yaitu sebesar 0,000 $<$ 0,005). Hasil analisis pearson correlation menunjukan hasil 0,930 yaitu tingkat hubungan antara Pengelolaan Obat dan kinerja adalah sempurna. 
Borneo Journal of Phamascientech, Vol. 04, No. 01, April Tahun 2020

ISSN-Print. 2541-3651

ISSN-Online. 2548 - 3897

Research Article

Untuk mengetahui faktor yang paling berhubungan terhadap Pengelolaan Obat RSUD XYZ, maka dilakukan analisis multivariat antara variabel bebas dengan variabel terikat. Dengan melihat nilai B, hasil penelitian menunjukan bahwa dari 4 variabel yang diuji secara bersamaan faktor yang paling dominan adalah Internal Bisnis ( $\mathrm{B}=1,239)$.Hasil analisis hubungan Kinerja terhadap Pengelolaan Obat Instalasi

Tabel VI. Variabel Penelitian 3

\begin{tabular}{|r|l|l|l|}
\hline No & Variabel Penelitian & B & P \\
\hline 1 & Keuangan & 0,664 & 0,178 \\
\hline 2 & Pelanggan & 1,012 & 0,15 \\
\hline 3 & $\begin{array}{l}\text { Pertumbuhan Dan } \\
\text { Pembelajaran }\end{array}$ & 0,988 & 0,016 \\
\hline 4 & Internal Bisnis & $\mathbf{1 , 2 3 9}$ & 0,003 \\
\hline
\end{tabular}

\section{Uji Korelasi Pengelolaan Obat} dan kualitas pelayanan kesehatan terhadap kinerja

Tabel VII. Uji Korelasi 4

\begin{tabular}{|l|c|r|r|r|c|}
\hline \multirow{2}{*}{} & & & & \multicolumn{2}{|c|}{$95 \%$ C.I.for EXP(B) } \\
\cline { 5 - 6 } & B & df & Sig. & Lower & Upper \\
\hline IM & 1,530 & 1 &, 043 & 2,145 & $9,038$. \\
\hline KPK & 1,165 & 1 &, 013 & 1,261 & $8,021$. \\
\hline Constant & - & & & & \\
& 2,659 & 1 &, 000 & & \\
& & & & & \\
\hline
\end{tabular}

Hasil analisis menunjukan bahwa terdapat hubungan Pengelolaan Obat dan kualitas pelayanan kesehatan terhadap kinerja. Hasil analisis menunjukan signifikansi hubungan yang sangat kuat antara Pengelolaan Obat dan kualitas pelayanan kesehatan dengan kinerja yaitu sebesar 0,043 dan 0,13 ( $<0,005)$. Hasil analisis Multivariat menunjukan hasil yaitu tingkat hubungan antara Pengelolaan Obat dan kualitas pelayan kesehatan terhadap kinerja adalah sempurna.

Tabel VIII. Variabel Penelitian 4

\begin{tabular}{|r|l|c|c|}
\hline No & $\begin{array}{l}\text { Variabel } \\
\text { Penelitian }\end{array}$ & B & P \\
\hline 1 & Keuangan & 0,664 & 0,178 \\
\hline 2 & Pelanggan & $\mathbf{1 , 0 1 2}$ & 0,15 \\
\hline 3 & $\begin{array}{l}\text { Pertumbuhan Dan } \\
\text { Pembelajaran }\end{array}$ & 0,988 & 0,016 \\
\hline 4 & Internal Bisnis & $\mathbf{1 , 2 3 9}$ & 0,003 \\
\hline
\end{tabular}

\section{KESIMPULAN}

Berdasarkan Hasil Penelitian dan Pembahasan , maka kesimpulan dalam penelitian ini adalah sebagai berikut :

1. Ada hubungan Pengelolaan

Obat Instalasi Farmasi (p 0,00) terhadap Kualitas Pelayanan 
Borneo Journal of Phamascientech, Vol. 04, No. 01, April Tahun 2020

ISSN-Print. 2541-3651

ISSN-Online. 2548 - 3897

Research Article

Kesehatan RSUD XYZ dengan nilai sebesar 0,964 .

2. Ada hubungan Kualitas

Pelayanan Kesehatan (p 0,00) terhadap Kinerja dengan nilai sebesar 0,930 .

3. Ada hubungan Pengelolaan Obat $(\mathrm{p}<0,05)$ terhadap Kinerja dengan nilai sebesar 0,915 .

4. Ada hubungan Pengelolaan Obat dan kualitas pelayanan kesehatan terhadap kinerja dengan nilai sebesar 0,915 .

\section{SARAN}

Untuk meningkatkan jumlah pasien yang memanfaatkan Instalasi Farmasi RSUD XYZ, maka pihak RSUD perlu :

1. Menjaga kebersihan gedung, melengkapi obat sesuai permintaan pasien, serta seluruh karyawan memakai seragam agar terlihat bersih dan rapih.

2. Pengadaan obat bervariasi terutama untuk obat yang sering digunakan.

3. Meminimalisir keterlambatan surat pesanan obat ke distributor farmasi agar tidak terjadi kekosongat obat.

\section{DAFTAR PUSTAKA}

A. Gde Muninjaya, Manajemen Mutu Pelayanan Kesehatan (Jakarta: EGC, 2011), halaman 10- 11

Aditama ,Tjandra Yoga. 2007. Manajemen Administrasi Rumah Sakit. UI : Depok

American Society Of Health-System Pharmacists. 1995. AHSP. Guidline On Advers Drug Reaction Monitoring And reporting. Am. J. Health-Sys. Pharm.

American Society Of Health-System Pharmacists. 1995. AHSP. Guidline On Advers Drug Reaction Monitoring Andreporting. Am. J. HealthSys. Pharm.

Azrul Azwar, Pengantar Administrasi Kesehatan (Jakarta: Binarupa Aksara, 1996), Cet.13. ke-1,hal.35.

Bringham,E.F., Houston,J.F.,1998. Fundamntals of Financial Management. 8 ed University Of Florida Press.

Bringham,E.F., Houston,J.F., 1998. Fundamntals of Financial Management. 8 ed University Of Florida Press.

Departemen Kesehatan RI. SK Menkes No. 1333, 1999 
Borneo Journal of Phamascientech, Vol. 04, No. 01, April Tahun 2020

ISSN-Print. 2541-3651

ISSN-Online. 2548 - 3897

Research Article

tentang Standar Pelayanan RS Depkes RI, Jakarta.

Departemen Kesehatan RI. UndangUndang Republik Indonesia Nomor 36 Tahun 2009 Tentang Kesehatan. Jakarta: Kementrian Kesehatan RI: 2009

Fauzi, 1995, Kamus Akuntansi Praktisi, Surabaya : Indah.

Gaspeerz, S., 2002. Manajemen Kualitas dalam Industri Jasa : Strategi untuk Memenangkan Persaingan Global, cet.3, PT Gramedia Pustaka Utama, Jakarta

Gaspeerz, S., 2002. Manajemen Kualitas dalam Industri Jasa : Strategi untuk Memenangkan Persaingan Global, cet.3, PT Gramedia Pustaka Utama, Jakarta

Gemala R. Hatta, Pedoman Manajemen Informasi Kesehatan di Sarana Pelayanan Kesehatan, (Jakarta: UI Press, 2008), h. 37.

Ghozali, Imam. 2005. Aplikasi Analisis Multivariate Dengan Program SPSS. Edisi Ketiga. Semarang: Badan Penerbit Universitas Diponegoro.

Ghozali, Imam. 2005. Aplikasi Analisis Multivariate Dengan Program SPSS. Edisi Ketiga. Semarang: Badan Penerbit Universitas Diponegoro.

Giatiningrum, A., 2009, Pengukuran Kinerja Perusahaan dengan Pendekatan Balanced Scorecard pada Perspektif Pembelajaran dan Pertumbuhan ( Studi kasus PT X), Institut Pertanian Bogor, Bogor.

Giatiningrum, A., 2009, Pengukuran Kinerja Perusahaan dengan Pendekatan Balanced Scorecard pada Perspektif Pembelajaran dan Pertumbuhan ( Studi kasus PT X), Institut Pertanian Bogor, Bogor.

Hanuma,S., dan Kiswara, E.2010, Analisis Blanced Scorecard Sebagai Alat Pengukur K

ISFI, 2004. Standar Kompetensi farmasi Indonesia, Jakarta

Kuncoro, M.,2003, Metode Penelitian Kuantitatid, UPP AMP YKPM, Yogyakarta

Machfoedz, M., 1996.Akuntansi Manajemen. Sekolah Tinggi Ilmu Ekonomi Widya Wiwaha, Yogyakarta.

Maimun, A., 2008. Perencanaan Obat Antibiotik Berdasarkan Kombinasi Metode Konsumsi Dengan Analisis ABC dan reorder Point Terhadap Nilai Persediaan dan Turn Over Ratio di IFRS Darul Istiqomah Kaliwungu Kendal, Naskah publikasi Magister Ilmu Kesehatan Masayrakat Konsentrasi Administrasi Rumah Sakit Program Pascasarjana UNDIP, Semarang.

Mujilan, 2012, Analisis Laporan Keuangan dan Rasio Keuangan : Memahami Infprmasi dan NonAkuntansi untuk Pengambilan 
Borneo Journal of Phamascientech, Vol. 04, No. 01, April Tahun 2020

ISSN-Print. 2541-3651

ISSN-Online. 2548 - 3897

Research Article

Keputusan, Universitas Widya Mandala Madiun.

Word Health Organization, Geneva.

Pham, K., 2004. Introducing the Scorecard to pharmacy benefit managers. Tesis Masters og Public Administration, Texas State University, Texas. Available at: http//www:yahoo.com

Sasongko, P.D. 2002. Kajian Perubahan Fungsi Taman Kota di Kota Semarang. Skripsi. Semarang: Universitas Diponegoro.

Satibi, Furdiyanti, N.h., dan Rahmawati,M.2007, Evaluasi Kinerja Suatu Apotek $\mathrm{X}$ di Yogyakarta dengan Pendekatan Balanced Scorecard., Majalah Farmasi Indonesia, 18(2):71-80, Universitas Gadjah Mada, Yogyakarta.

Situmorang S.H., dkk, 2008. Analisis Data Penelitian, Medan: USU Press.

Srimindati, C., 2005, Balanced Scorecard Sebagai Alternatif Untuk Mengukur Kinerja, http://www.stiestikubank.ac.id/webjurnal,2007

Wahyuni, S.2011,Analisis Balanced Scorecard Sebagai Alat Pengukuran Kinerja Pada PT. Semen Bosowa Maros, University Hasanudin, Makasar.

WHO,1993. How to Investigate Drug Use in Health Facilities, Selected Drug Use Indicator, Action Programme on Essential Drug. 